\title{
Redimensionamento do espaço e do tempo: a incerteza e os desafios da sociedade, da informação e do planejamento do marketing
}

\author{
Roberto Vilmar Satur* \\ Júlio Afonso Sá de Pinho Neto** \\ Emeide Nóbrega Duarte**
}

Artículo recibido:

12 de abril de 2018

Artículo aceptado:

21 de septiembre de 2018

Artículo de revisión

\section{Resumen}

Este artículo tiene el objetivo de contextualizar lo que la posmodernidad reserva para la sociedad y para lo social, desde la perspectiva de la información y del marketing. La información, que ejerce la función esencial de alimentar las estrategias de marketing, cambia en conjunto con el ambiente, en consecuencia, si el ambiente es posmoderno, la información tendrá esas características también. Como el marketing actúa en el escenario vigente, necesita actualizarse para ese nuevo contexto adecuando todas sus formas de actuación. Considerando un ambiente donde el tiempo se ha transformado en el ahora, y el espacio es el aquí, queda una interrogación muy grande sobre si es posible todavía planificar en ese

* Departamento de Mediações Interculturais, Universidade Federal da Paraíba, Brasil robertosatur@yahoo.com.br

** Programa de Pós-Graduação en Ciência da Informação, Universidade Federal da Paraíba, Brasil_sadepinho@gmail.com emeide@hotmail.com

INVESTIGACIÓN BIBLIOTECOLÓGICA, vol. 32, núm. 77, octubre/diciembre, 2018, México, ISSN: 2448-8321 pp. 151-173 
contexto. Los cambios tecnológicos han contribuido a acortar la perspectiva del tiempo y el espacio, de modo que se tiende a que todo sea pensado y hecho en ese contexto, incluso el marketing y su necesario uso de la información. Este artículo estudia algunas tendencias de ese ambiente posmoderno, de esos cambios y sus impactos en la perspectiva del marketing y de la información. Finaliza construyendo la perspectiva acerca de cómo debe ser concebida la planificación estratégica del marketing y el uso de la información en ese nuevo contexto social, en una construcción reflexiva que no descarta una de las principales características de la posmodernidad: la incertidumbre.

Palabras clave: Información; Sociedad Posmoderna; Espacio-tiempo; Incertidumbre; Marketing

Re-dimensioning space and time: The uncertainty and challenges in society, information and marketing planning

Roberto Vilmar Satur, Júlio Afonso Sá de Pinho-Neto and Emeide Nóbrega-Duarte

\section{Abstract}

This article aims to contextualize what postmodernity holds for society in terms of information and marketing planning. The information, which plays an essential role in development of marketing strategies, changes hand in hand with the environment. As such, if the environment is postmodern, the information will exhibit postmodern features as well. The way marketing works, including strategic planning, must be upgraded in order to operate in this current scenario. In an environment where time and space mean the here and now, we may well ask if planning is even possible. Technological changes have served to telescope both time and space, and this exerts impacts on how marketing exploits information. This paper therefore examines some of the features of this postmodern environment, contextualizing their impact on both marketing and information usage, concluding by offering perspectives on how to conceive of strategic planning of marketing and the use of information in this new context, which does not ignore uncertainty as a major feature of postmodernity.

Keywords: Information; Postmodernity society; 


\section{INTRODUÇÃO}

Teste artigo, apresenta-se uma discussão teórica acerca dos novos desa1 fios que o marketing tem em seu objeto, que é a troca, especialmente no elemento que mais alimenta toda a sua estratégia, seu planejamento e sua ação, que é a informação, considerando o ambiente pós-moderno. Embora se saiba que muitos autores não consideram a atualidade como algo pós-moderno, tampouco uma transição, optou-se por chamar esse momento de "transição para a pós-modernidade" visando marcar a diferença atual com a do tradicional estilo moderno (metade do século XX e anterior) e o que está por vir que pode o período pós-moderno. Sem entrar no mérito do uso do termo pós-moderno, o fato é que se está em um ambiente de transição e de grandes mudanças. Nesse novo tempo o principal foco é a nova configuração de tempo e espaço e o papel das tecnologias.

Também é importante lembrar que, apesar do modismo da expressão pós-modernidade, sabe-se que muito do que existe ainda tem traços fortes da modernidade e nem se imagina que a pós-modernidade irá romper com tudo o que é moderno, muito menos descartá-los, partindo do zero. O novo ambiente se reconfigura sobre o atual, reutilizando alguns, descartando outros, mas, principalmente, mudando a forma de uso e as relações.

O marketing é uma das áreas da gestão que mais rapidamente se atualiza aos novos cenários. Isso porque uma de suas missões é estar atento ao que acontece em seu campo de atuação e rapidamente se readequar a ele. Se o ambiente atual é pós-moderno ou tende ao pós-moderno é evidente que a informação disponível, de que tanto o marketing precisa, será fruto desse ambiente. Cabe ao marketing entender e se conectar a esse novo momento para conseguir as informações.

Dentro dessa perspectiva, podem-se destacar algumas mudanças efetivamente ocorridas, entre elas, o tempo e o espaço que mudaram substancialmente, influenciados, sobretudo, pelo avanço da ciência e da tecnologia, que encurtou distâncias e tempo, com melhores recursos computacionais e melhores formas de comunicação e de transmissão de dados, informação e imagem em tempo real. Isso tem feito o virtual ocupar espaços antes exclusivos do real. Aliado a isso surgem mudanças de postura, de valores, de política, de economia, de relacionamento, de crenças e tantas mais.

\section{Metodologia}

Este artigo trata-se de um estudo com características de pesquisa qualitativa, de revisão teórica e propositiva, pois usa uma base de informações de 
natureza secundária (publicados) para explicar a nova dimensão que as tecnologias causaram no espaço, no tempo e sobre as informações e seu impacto no marketing, no seu planejamento e nas estratégias. E na última etapa do artigo ele é propositivo, pois tratam-se de construtos elaborados pelos autores do artigo de modo a deixar uma contribuição para o assunto em questão visando melhor entender a realidade atual para atuar nela. Com isso os autores dão um passo além do que já se conhece tradicionalmente, considerando, agora, um ambiente transacional para o pós-moderno, com novas dimensões de tempo e espaço, especialmente em relação à busca e ao uso da informação.

Este estudo qualitativo, que envolve pesquisa bibliográfica, pois reúne citações de um conjunto de materiais escritos, já elaborados e publicadas por outros autores, e também elabora proposta de entendimento sobre o caso estudado, pois finaliza com características de pesquisa-ação (propositiva), em que propõe formas de melhor entender a realidade e assim poder agir de forma mais eficaz, foi desenvolvida a partir de 2014 no Programa de Pós-Graduação em Ciência da Informação, e focava como estratégia a discussão sobre as mudanças das tecnologias, especialmente as da informação e da comunicação, sobre a realidade da sociedade atual e seus efeitos sobre a informação no seu contexto do planejamento do marketing, especialmente considerando o redimensionamento do espaço tempo e as incertezas decorrentes de tais mudanças.

Dentro desta estratégia buscou elencar algumas relevantes publicações e autores que abordassem as mudanças do tempo e espaço decorrentes do avanço tecnológico e o ingresso na pós-modernidade, discutindo o efeito disso sobre a informação e, por conseguinte o impacto destas mudanças sobre o planejamento e as estratégias do marketing. Evidentemente que aliou-se a isso reflexões sobre essas mudanças. Por essa razão os tópicos foram estrategicamente desenvolvidos com essa sequência lógica:

- (I) o marketing e a informação enfrentando ou absorvendo mudanças (o que está acontecendo). E para desenvolvê-lo após pesquisa teórica em diversos autores selecionou-se os que seguem por contribuirem com os propósitos desse item. Os selecionados para essa etapa foram: McKenna (1992); Santos (1988); Stewart (1998); Hooley, Saunders e Piercy (2001); Sabbag (2007); Sina (2008); Monteiro e Abreu (2009); Trigo, Soares e Quoniame (2012); Keegan e Green (2013); Sousa et al. (2013); Bembem, Santos e Pinho Neto (2014); Perrotti e Pieruccini (2014); Satur, Paiva e Duarte (2017) e a American Marketing Association (AMA, 2018). Embora esses não sejam os únicos autores da área, mas eles representam bem a discussão sobre o tema; 
- (II) mudanças do marketing em função da informação e do ambiente (os impactos e as repercussões). Para buscar responder a esse tema, após a revisão de teóricos com publicações de diversos anos chegou-se selecionou-se os autores que seguem: Freitag (1986); Santos (1988); Chesneaux (1989); Baudrillard (1992); Weissberg (1993); Quéau (1993); Virilio (1993); Serra (1998); Latour (1994) e Latour (2012); Lèvy (1999); Barreto (2005); Pinho Neto (2008); Vargo e Lusch (2011); reforçados com argumentos de Bourdieu (1997) e Sina (2008). O uso de autores a partir do final dos anos 80 e intensamente dos anos 90 para cá não é coincidência. É a contar dessa época que a academia (universidades, centros de pesquisa e pesquisadores) começam a dar maior atenção ao fenômeno oriundo das novas tecnologias e do redimensionamento espaço e tempo;

- (III) adequando o planejamento de marketing na pós-modernidade (tentativa de apontar o que se pode fazer a partir dessa nossa perspectiva). A partir do que os autores apresentaram como tendência os autores do presente artigo tentaram explicar essa perspectiva de uma forma didática e construíram construtos tentando demonstrar a nova realidade que se apresenta. Nessa parte a contribuição é dos autores do artigo, construindo uma proposta didática de entendimento da nova realidade, baseados nas leituras e releituras feitas nos autores.

\section{O MARKETING E A INFORMAÇÃO ENFRENTANDO OU ABSORVENDO MUDANÇAS}

A American Marketing Association (AMA), tem atualizado constantemente o conceito de marketing acompanhando as mudanças atuais. A última conceituação o define como "a atividade, ou conjunto de instituições e processos para a criação, comunicação, entrega e troca de produtos e serviços que têm valor para os consumidores, clientes, parceiros e a sociedade como um todo" (Keegan e Green, 2013: 6). Mesmo assim, a pós-modernidade sempre o desafiará a continuar se atualizando e sempre haverá déficit no conceito, porque conceito, normalmente, tem características estáticas.

Para evidenciar essas mudanças e, automaticamente, seu impacto no marketing, destacaram-se quatro subgrupos relevantes de mudanças percebidas. O primeiro inclui dez destaques de McKenna (1992); o segundo menciona as mudanças apontadas por Hooley, Saunders e Piercy (2001); o terceiro, um esboço de algumas mudanças destacadas por diversos outros autores. 
I) McKenna (1992) já alertava que existe um in que afeta diretamente o marketing na atualidade: a incapacidade de fazer frente ou de não perceber a habilidade de outro in, ou seja, os concorrentes intangíveis. A seguir os dez desses concorrentes in, citados a seguir de forma adaptada e com um complemento explicativo.

\begin{tabular}{|c|c|c|}
\hline Item & Concorrente in & Explicação básica \\
\hline 1 & Mudança & $\begin{array}{l}\text { Costuma aparecer sem perguntar se pode. } \\
\text { É ditadora. }\end{array}$ \\
\hline 2 & Resistência à mudança & $\begin{array}{l}\text { Temos mentalidade moderna, gostamos das } \\
\text { coisas como estão, ao menos por um bom tempo. }\end{array}$ \\
\hline 3 & Consumidores bem informados & $\begin{array}{l}\text { É fácil lidar com consumidores desinformados, } 0 \\
\text { contrário dá trabalho. E não se quer mais trabalho. }\end{array}$ \\
\hline 4 & A mente do consumidor & $\begin{array}{l}\text { Consumidor não se comporta apenas racionalmen- } \\
\text { te, mas também por conta do afeto, da emoção, do } \\
\text { ambiente e do momento. Perceber e medir isso é } \\
\text { difícil. }\end{array}$ \\
\hline 5 & A mentalidade da pasteurização & $\begin{array}{l}\text { A massificação da produção é boa para baixar } \\
\text { custos, mas, com o passar do tempo, todos farão } \\
\text { isso, entõ não haverá diferenciação, e a única forma } \\
\text { de concorrer será se digladiando pelos preços. } \\
\text { Assim, os ganhos são absorvidos pela concorrência } \\
\text { desenfreada. }\end{array}$ \\
\hline 6 & A mentalidade de grandeza & $\begin{array}{l}\text { Empresas grandes tendem a trilhar o caminho segu- } \\
\text { ro, de menos risco, produção em escala e acabam } \\
\text { inibindo a inovação, "atolando-se" na burocracia e } \\
\text { na massificação da produção e da venda. }\end{array}$ \\
\hline 7 & Cadeias rompidas & $\begin{array}{l}\text { Muitos esquecem que todas as situações estão } \\
\text { inter-relacionadas e acabam priorizando algumas } \\
\text { etapas da cadeia, que vai do produtor ao consu- } \\
\text { midor. No entanto, numa rede de relações, a força } \\
\text { da cadeia é medida pelo elo mais fraco dela, e é } \\
\text { grande a chance de esse elo ser exatamente o que } \\
\text { foi esquecido. } 0 \text { elo mais fraco dará o ritmo de toda a } \\
\text { cadeia, independente dos outros serem fortes. }\end{array}$ \\
\hline 8 & 0 conceito do produto & $\begin{array}{l}0 \text { próprio conceito de produto, se não for atualizado, } \\
\text { torna-se um concorrente, uma dificuldade. } 0 \text { que } \\
\text { se vende na atualidade são serviços, satisfações. } \\
0 \text { produto é apenas um artefato que carrega em si } \\
\text { tais serviços e satisfações. Focar no produto não } \\
\text { funciona adequadamente. }\end{array}$ \\
\hline 9 & $\begin{array}{l}\text { Coisas que aparecem da noite } \\
\text { para o dia }\end{array}$ & $\begin{array}{l}\text { Foi um iceberg que afundou o Titanic, ele apareceu } \\
\text { da noite para o dia. Todo dia aparecem novos "ice- } \\
\text { bergs" nas organizações e no ambiente profissional. }\end{array}$ \\
\hline
\end{tabular}




\begin{tabular}{|l|l|l|}
\hline 10 & Você (eu) & Você pode ser o seu concorrente mais difícil. Má- \\
& quinas e produtos não competem, mas as pessoas \\
& competem entre si, ou contra si. Usam produtos e \\
& máquinas para isso. Ao subestimar suas ideias, ao \\
& não ter autoconfiança ou ao achar que é infalível, \\
& que sabe tudo, ao não querer mudar, você concorre \\
& contra você mesmo. \\
\hline
\end{tabular}

Quadro 1. Os concorrentes in do marketing

Fonte: Adaptado de McKenna (1992), com agregações dos autores

II) Juntam-se a todos esses "in" outros fatores que reforçam o ambiente de mudança e de complexidade que a pós-modernidade traz consigo, gera-se uma situação em que não se pode querer mudar, mas é preciso fazê-lo. Hooley, Saunders e Piercy (2001) destacam alguns fatos relevantes nesse sentido:

\begin{tabular}{|c|l|}
\hline Item & \multicolumn{1}{c|}{ Ambiente de mudança } \\
\hline 1 & $\begin{array}{l}\text { Enquanto a Revolução Industrial levou } 60 \text { anos para dobrar a produtividade por } \\
\text { pessoa, a China e a Coreia do Sul conseguiram fazer isso em } 10 \text { anos. }\end{array}$ \\
\hline 2 & $\begin{array}{l}\text { 0 que se gera de inovação e conhecimento novo por ano, na atualidade, fruto de } \\
\text { pesquisa e de desenvolvimento, supera todo o conhecimento gerado até os anos } \\
60, \text { ao menos em quantidade. }\end{array}$ \\
\hline 3 & $\begin{array}{l}\text { Os fabricantes de computadores reduzem em 30\% os custos por ano para } \\
\text { continuar competitivos. }\end{array}$ \\
\hline 4 & $\begin{array}{l}\text { Consumidor mais informado é mais exigente, quer mais pagando menos. Está } \\
\text { também querendo que empresas tenham compromissos adicionais (sustentabili- } \\
\text { dade, direitos humanos). }\end{array}$ \\
\hline 5 & $\begin{array}{l}\text { Consumidores estão migrando para ofertas de valor alternativo, e não, somente, 0 } \\
\text { modo clássico de valor. }\end{array}$ \\
\hline 6 & $\begin{array}{l}\text { Restaram dois tipos de organização: as que têm departamento de marketing } \\
\text { (moderna) e estão, aos poucos, desaparecendo e as que têm alma de marketing, } \\
\text { que respiram marketing no todo da organização. }\end{array}$ \\
\hline
\end{tabular}

Quadro 2. Mudança não é uma questão de escolha, mas de necessidade e velocidade Fonte: Adaptado de Hooley, Saunders e Piercy (2001), com agregações dos autores

III) Podem-se destacar, ainda, outros autores que trazem exemplos tão importantes como os anteriores e reforçam esse cenário de mudanças.

\begin{tabular}{|c|l|}
\hline Item & \multicolumn{1}{|c|}{ Ambiente de mudança acelerado pela tecnologia } \\
\hline 1 & $\begin{array}{l}\text { A cada dois dias, o Yahoo grava 24 terabytes de informações sobre o que fizeram } \\
\text { seus usuários. (Keegan e Green, 2013) }\end{array}$ \\
\hline 2 & $\begin{array}{l}\text { De 2003 a 2010, na China, o número de usuários de internet saltou de } 68 \text { bilhões } \\
\text { para 450 bilhões. Isso transformou esse país no maior e-commerce do mundo. } \\
\text { (Keegan e Green, 2013) }\end{array}$ \\
\hline
\end{tabular}




\begin{tabular}{|c|c|}
\hline 3 & $\begin{array}{l}\text { Gutenberg transformou todo o mundo em leitor, a Xerox transformou todo o } \\
\text { mundo em editora, os PCs transformaram todo o mundo em escritores, e a inter- } \\
\text { net transformou todo o mundo em atores, co-criadores e produtores em redes } \\
\text { digitais. (Keegan e Green, 2013) }\end{array}$ \\
\hline 4 & $\begin{array}{l}\text { Em 1981, Bill Gates dizia que } 640 \text { kilobytes eram mais do que suficientes para } \\
\text { qualquer um. Em 1977, Ken Olson, da Digital Equipment Corp., dizia não ter } \\
\text { razões de alguém querer ter um computador em casa. E o presidente da IBM, } \\
\text { Thomas Watson, em 1943, disse: "Penso que há, talvez, no mundo, um mercado } \\
\text { para cinco computadores". Erraram, todos os seus prognósticos. } 0 \text { sucesso das } \\
\text { empresas tecnológicas foi tão significativo que, atualmente, tem uma bolsa de } \\
\text { valores exclusiva para elas: Nasdaq. (Sina, 2008: 17-18) }\end{array}$ \\
\hline 5 & $\begin{array}{l}\text { Várias estimativas mostram a ordem de grandeza de vários exabytes (1018 bytes) } \\
\text { de nova informação de que, todos os anos, é colocada na web, crescimento } \\
\text { acima dos } 20 \% \text { anuais. Isso significa que, mesmo se considerarmos a divisão } \\
\text { em disciplinas no conhecimento, a quantidade de informação nova disponível } \\
\text { em cada segmento do conhecimento ultrapassa as capacidades de absorção do } \\
\text { cérebro humano. (Trigo, Soares e Quoniame, 2012: 67) }\end{array}$ \\
\hline 6 & $\begin{array}{l}\text { Em 1994, tempos, ainda, de início da internet, já se dizia: "[...] na internet, } \\
\text { tudo se passa tão rapidamente que um ano civil correspondiam a sete anos de } \\
\text { evolução na internet. Essa realidade é, hoje, ainda mais complexa, uma vez que } \\
\text { passamos para níveis de velocidade nos quais um ano na internet corresponde a } \\
\text { 10, } 15 \text { ou, até mesmo, } 20 \text { anos civis". (Trigo, Soares e Quoniame, 2012: 67) }\end{array}$ \\
\hline 7 & $\begin{array}{l}\text { "todos os anos, são produzidos aproximadamente 1,5 bilhões de gigabytes, } \\
\text { armazenados nos mais variados suportes de informação, o que fornece em média } \\
\text { de } 250 \text { megabytes de informação para cada ser humano". (Reis, 1997, em Sousa } \\
\text { et al., 2013: 9) }\end{array}$ \\
\hline 8 & $\begin{array}{l}\text { Na pós-modernidade, robôs dançam valsas, temos som de flauta que não vem } \\
\text { da flauta, computadores fazem trilhões de operações por segundo, máquinas } \\
\text { registram nanossegundos, coisas que a mente humana não daria conta sozinha, } \\
\text { nem no tempo e nem no espaço. (Santos, 1988) }\end{array}$ \\
\hline 9 & $\begin{array}{l}\text { “[...] metade do que o calouro de engenharia aprende ao entrar na faculdade } \\
\text { estará obsoleto quando ele se formar; a obsolescência do conhecimento em ele- } \\
\text { trônica é tão rápida que os especialistas em informática usam a expressão 'idade } \\
\text { da internet' da mesma forma que as crianças falam em 'idade de cachorro'”. } \\
\text { (Stewart, 1998: 63) }\end{array}$ \\
\hline 10 & $\begin{array}{l}\text { O tempo entre a descoberta científica e sua transformação em produto tecnológi- } \\
\text { co diminuiu } 60 \% \text { do início do Século XX até o final deste. (McKenna, 1992) }\end{array}$ \\
\hline
\end{tabular}

Quadro 3. Mudança ainda mais velozes com o advento da tecnologia computacional e da internet Fonte: Adaptado dos diversos autores citados no quedro

Quem entender bem e mais rapidamente tudo isso, se é que é possível usar a palavra 'tudo', terá vantagem, pois pode se antecipar utilizando novas estratégias de marketing ou atualizando as anteriores.

Como já mencionado, o objeto do marketing são as trocas, e seu objetivo é de agregar valor, dentro de sua cadeia, em curto e em longo prazo para todos os envolvidos no processo ou atingidos por ele. Para isso, o marketing 
faz gestão de promessa e de expectativas. Promessa se faz com informações, e expectativas se criam pelas promessas feitas. O desafio da gestão do marketing é de garantir que o produto ou o serviço entregue garanta que seus atributos confirmem as expectativas geradas pela promessa, porquanto o consumidor não compra mais produtos e serviços, mas o benefício que ele gera. É um desafio complexo no ambiente descrito acima, com tantas mudanças e com o consumidor cada vez mais informado, exigente e inquieto, digamos, pós-moderno.

No marketing, fala-se em local de origem (espaço) como algo que pode ser utilizado como estratégia. Mas com as novas tecnologias e o ciberespaço, ficou difícil manter isso estático. Todos os lugares fazem trocas, compram e vendem. Com o ciberespaço e a internet, as trocas continuam ocorrendo, mas é difícil dizer o "lugar" da ocorrência. Redefiniu-se o espaço: a empresa pode estar no principal centro comercial físico do mundo ou em um quartinho no fundo de uma casa, em qualquer país que o processo de consulta, acesso e negociação online é o mesmo e independe do cliente pode ser o vizinho da empresa ou estar há milhares de quilômetros de distância. Compra-se, e o produto, em muitos casos, será entregue pela própria rede mundial de computadores, via download ou login com senha exclusiva de acesso online. $\mathrm{O}$ que continua distinto ainda é o processo de entrega quando ela é física e exige deslocamentos dos produtos ou das pessoas (em caso de viagens e turismo). Mas é inegável que a comercialização ganhou um novo espaço de atuação, o ciberespaço. E se for serviço, o ciberespaço pode ser também espaço de entrega.

Expandir negócios agora não envolve apenas abrir filiais em novos espaços físicos, contratar mais representantes e outros. A expansão pode ser a implantação de um novo site na internet que permita e-commerce. A noção de local para instalar a nova filial ganhou um concorrente de peso: o ciberespaço.

A Amazon Books é um exemplo de uma empresa que preferiu o mercado virtual em detrimento do físico, consolidou-se no mercado mundial e continua apostando mais nas indicações do cliente sem investir em publicidade. O sucesso da empresa é inquestionável. O que não se sabe é se, na era digital, ainda poderia se chamar de "boca a boca". Já o Google busca também lucros no mercado virtual, mas aposta na publicidade como um desses meios. Também é um sucesso contundente (Sina, 2008). Isso para ficar em apenas dois exemplos de muitos outros possíveis.

Com ou sem publicidade, ambas não prescindem do marketing, da tecnologia e da informação como instrumentos e fatores fundamentais à sua atuação, e isso lhes garante o sucesso. Esse processo elimina a necessidade de grandes investimentos físicos, equipe de vendas de plantão à espera de que o 
cliente entre pela porta. Também permite eliminar grandes estoques e custos logísticos desnecessários, pois pode fazer a venda e, a partir dela, disparar a ordem de entrega direto do próprio fornecedor. Assim, o produto sai do fornecedor direto para o cliente sem ter passado pela empresa que o vendeu.

Não se atua mais no mesmo mercado, ou melhor, não existe somente o mesmo mercado. Trata-se do espaço (mundo) virtual e do espaço (mundo) real que se complementam. É o ciberespaço, com suas múltiplas formas possíveis de interação e de convivência, que mudou a noção de estar no espaço, de circular por ele, de interagir nele.

Pelas plataformas digitais e a inteligência coletiva, assimila-se a informação, cujo foco é a construção do conhecimento, por meio da cooperação, da troca de informações e de comunicação com a interação em rede. Assim, a sociedade e a tecnologia produzem o indivíduo, que também as produz, pela interação. Por essa razão, a tecnologia não pode ser vista como ameaça, tampouco como salvadora, mas como facilitadora das relações e das interações humanas, nesse novo tempo e espaço do aqui e agora (Bembem, Santos e Pinho Neto, 2014). Nesse novo dimensionamento se criam "vínculos simbólicos entre os deferentes, espaços de transição, pontos de convivência que tornam possível o 'viver juntos', em especial em época de mudanças que alteram relações de tempo e espaço, via tecnologias virtuais" (Perrotti e Pieruccini, 2014: 11).

Nessa perspectiva, segundo Monteiro e Abreu (2009: 1) ocorrem agenciamento maquínicos, muito característico do pós-moderno. Não se trata de uma oposição homem $x$ máquina mas sim de um contexto "onde homem e máquina e signos se hibridizam nas múltiplas maneiras de organizar e buscar o conhecimento no ciberespaço, seja por meio da etiquetagem social, seja por ontologias ou pelos mecanismos de busca". Homem e máquina convivem em plena interação, complementam-se e utilizam esses avanços. Evidente que todo o restante foi ao menos perturbado com tais mudanças, pois dizer que tudo mudou seria um pouco pretensioso.

O ciberespaço trouxe o espaço para perto, e a Internet nos inundou de dados e informações nunca antes vistos. "[...] em nenhum outro período da história, as respostas podem antecipar-se às questões, uma vez que os cenários estão realmente diante dos olhos dos executivos, tamanha é a quantidade de informação disponível" (Sina, 2008: 320). Então, se a informação está mais próxima e imediata como nunca antes visto, em quantidade e, de alguma forma, em qualidade, vale a tendência apontada por Harris de que, segundo Sabbag (2007), a relevância da informação na atualidade tem se sobressaído tão grandemente em relação aos demais fatores e variáveis que está tomando o lugar da autoridade nas relações interpessoais, inter e intraorganizacionais. 
Mas, junto com a quantidade demasiada de informações disponíveis, é possível detectar um expressivo número de informações inúteis, enganadoras, ambíguas, assimétricas, incompletas, imperfeitas, excessivas, complexas, dúbia, duplas, insinuantes, contraditórias e falsas (Satur, Paiva e Duarte, 2017). A informação, que veio para facilitar as ações de marketing, diante do excesso, também tem exigido melhores critérios e mais empenho para selecioná-la e classificá-la, com filtro, procurando "agulhas dentro de um palheiro".

\section{MudanÇAS Do MARKETING EM FUnÇÃo DA INFORMAÇÃO E DO AMBIENTE}

No método tradicional, o marketing utiliza um modelo sequencial e lógico de planejamento: primeiro, busca conseguir informações suficientes; depois, procura pensar estrategicamente sobre seu planejamento no tempo e no espaço. Somente depois ocorre a ação, e finalmente, a avaliação dos resultados para readequar o planejamento. Todavia, no ambiente pós-moderno, tudo acontece agora, aqui. O tempo tende a se contrair na instantaneidade. Nessa nova reconfiguração, tudo acontece ao mesmo tempo, num espaço remodelado.

O marketing sempre está em busca de informações e assim continuará, especialmente as emitidas pelos atores (consumidores, stakebolders, usuários). Nesse novo cenário, é preciso perceber que esses atores também mudaram seu comportamento e o espaço onde circulam. Além do fato de que as trocas de informações ocorrem com rapidez, independentemente de ela estar perto ou longe, ser do passado, do presente ou uma projeção do futuro também precisa se considerar a busca por informação precisa seguir a lógica de Latour (1994 e 2012), que envolve seguir rastros, suspeitas deixadas pelos atores que liberam a informação. Isso afeta sobremaneira a perspectiva clássica de mensurar, medir e projetar. E afeta ainda mais ao saber que os rastros e as suspeitas não estão mais apenas no espaço físico mas também no ciberespaço.

A complicação ou complexidade aumenta quando o próprio ator não está entendendo muito bem o seu novo espaço. Sobre isso, pode-se reportar a Chesneaux (1989), que afirma que o bomo mundialis modernicus anda desorientado com essa modernidade. Ele está constrangido com os ajustes temporais ávido de ganhar tempo: a sociedade de consumo consome muito tempo. Ele está frustrado, neurótico e tenso. Está ocupadíssimo, fazendo muitas coisas ao mesmo tempo e clama por tempo livre. Mas, quando tem tempo livre, fica com a impressão de que está perdendo tempo. Trata-se de uma sociedade sincrônica integral. O tempo virou um sistema que permite fugir do real, com o advento do virtual que, em muitos casos, confunde-se com esse 
real e até é mais agradável do que ele. E pelo virtual pode-se ir para o passado e para o futuro no mesmo instante. O espaço também mudou, pois, com a virtualidade, é possível viajar pelo mundo acessando um computador. $\mathrm{O}$ mundo agora está "aqui". O tempo e o espaço deram lugar ao prazo (Chesneaux, 1989). E normalmente esse prazo é o agora.

Trata-se de um ambiente imediatista, angustiado e confuso. Como afirma Virilio (1993), a pós-modernidade gerou uma confusão entre o mundo real e o virtual, como tempo e espaço. Fusão de vários lugares ao mesmo tempo, além das aparências sensíveis. Com a virtualidade, não há mais tempo fixo no espaço. Vive-se numa transparência ou trans-aparência transmitida a distância instantaneamente, em que os pixels das imagens são transmitidos e recebidos pela tele-ação, tele-audição, tele-visão.

Relembrando Latour (2012), que recomenda seguir rastros e suspeitas para identificar o comportamento dos atores. Nesse cas,o surge uma pergunta: como seguir suspeitas e rastros das informações deixadas pelos atores nesse contexto? Afinal, o rastro e a suspeita podem ser tão somente uma imagem, um simulacro, uma aparência.

$\mathrm{O}$ ator que emite informações é um ser que atua nesse novo ambiente com o tempo e o espaço redimensionados e recriados. Todavia não significa que é um ator mais autônomo. Na verdade, a alienação continua e agora é provocada pela Ciência, pela tecnologia, pela aparência e pela imagem. Nela a razão se voltou contra quem a pensou, e a razão abrangente e humanista se atrofiou (Freitag, 1986).

Logo, o planejamento estratégico de marketing abrangente, racional, focado na essência pode ter problemas ao retratar esse contexto. Pois, corre-se o risco de se focar num ator alienado que somente foca $n$ aparência e na imagem.

Ou seja, avanço da tecnologia e da Ciência não garantiu a tão sonhada autonomia do cidadão, mas facilitou a condição para que a sociedade aderisse a uma cultura, a um consumo e a um comportamento de massa, sem posições e reflexões políticas profundas. Não garantiu a libertação, mas fortaleceu a dominação, a alienação e a sedução. Uma espécie de autonomia ao contrário. Nesse contexto, por exemplo, ganha a eleição quem usar as informações de modo a promover o melhor espetáculo, com um show agradável aos olhos e aos ouvidos do eleitor. Assim, os partidos viram "produtoras de publicidade" e os candidatos "mercadorias" a serem vendidas (Serra, 1998).

A ética do marketing tem defendido que as ações de marketing devem evitar explorar públicos vulneráveis. Tradicionalmente se conhecia públicos vulneráveis como sendo crianças, idosos, deficientes, pessoas com déficit educacional etc. Ou seja, pessoas com fragilidades financeiras, psíquicas, emotivas, etc. Isso também envolvia pessoas com estado emocional alterado, 
endividados, pessoas sob pressão, carentes de afetividade, ignorantes ou desinformados sobre aquela assunto, com dependência química, compulsivos e outros. O marketing ético defende que não se pode usar da fragilidade das pessoas para as convencer a fazer algo que não seria o melhor para elas. No entanto, na pós-modernidade isso fica ainda mais complexo por que, se considerarmos a alienação como uma fragilidade, praticamente toda a população poderia ser considerada vulnerável ou em estado de vulnerabilidade, ao menos em algumas situações.

Soma-se a isso exclusão do acesso ao saber como um estado de vulnerabilidade, que se intensificou com as novas mídias. Embora as redes informacionais permitem um maior acesso à novas formas de ensino, à novas aprendizagem, à mais informação e à mais conhecimento, ainda assim, a exclusão persiste (Serra, 1998). Pois novas exclusões foram geradas levando em conta que muitos não têm acesso a esses recursos, outros não sabem os usar plenamente e muitos estão conformados em viver na sociedade do espetáculo, da informação superficial, do modelo de consumo em massa. Nessa perspectiva, fica difícil definir até onde vai a vulnerabilidade que o marketing não pode eticamente explorar.

Soma-se a isso o fato de que, na chamada pós-modernidade, o consumo deixou de ser gozo, necessidade e prazer, para ser um fazer gozar por objetos, serviços e especialmente signos. Faz-se de tudo que se quer, manipula-se, controla-se. Comunicar não é mais falar, mas fazer-falar; informação não é saber, mas fazer-saber. O verbo fazer (operacional) e não mais o de ação (crer, gozar, consumir, agir) tomou a dianteira de tudo. Tudo agora é fazer-agir, fazer-crer. E mesmo que o indivíduo não queira, será convencido a se fazer-querer. $\mathrm{O}$ fazer por persuasão ou dissuasão. O verbo ação deu lugar definitivo ao verbo operacional (fazer), que é algo produzido, induzido, solicitado, manipulado, tecnificado, midiatizado. A comunicação é, agora, o fazer-comunicação. A informação é o fazer-informação, do contrário, ela não repercutirá (Baudrillard, 1992).

Pode-se dizer, então, que o agir do marketing também passou a ser o fazer-marketing. E se faz com serviços. As pessoas não compram produtos, mas serviços, o benefício que ele proporciona. O objeto é apenas o artefato que carrega em si os atributos que permitem que tal benefício. Segundo Vargo e Lusch (2011), no mercado, tudo agora é B2B (business to business) e envolve A2A (ator a ator), num sistema em rede, em que se foca a criação de valor. Está em voga a lógica dominante em serviços (SDL), segundo a qual todos nós somos dependentes das relações e dos serviços que os outros nos prestam e vice-versa. Somos todos seres que servem e são servidos, pelas especialidades. Assim, ficamos todos entrelaçados por um emaranhado de 
redes interdependentes. Ao propor o B2B no lugar de B2C (empresa versus consumidor), é porque, no $\mathrm{B} 2 \mathrm{C}$, o consumidor tem um papel mais passivo na troca, enquanto no B2B, ambos são "business", atuantes. Já o termo A2A, é mais adequado em tempos de SDL. Na perspectiva A2A e B2B todos os atores estão cocriando valor em marketing, num ambiente em rede e de lógica dominante em serviços (SDL). Trata-se de um ecossistema de serviços e/ou serviços ecopensados, de SDL como evolução orgânica.

Prevalece a interação em rede, as sociedades em rede, a cibercultura, o ciberespaço, o lócus virtual pela noosfera, a convergência de ideias de percepções e memórias (com base na perspectiva de Lèvy, 1999). É a sociedade da informação que usa as TICs, na tecnoeconomia e gera uma nova forma de superar a crise capitalista, permitindo uma nova fase de acumulação e de crescimento. Novas formas de reproduzir o capital (Barreto, 2005).

Também mudou a perspectiva de tamanho, que deixou de ser parâmetro para o real. Para Virilio (1993), tudo, de todos os tamanhos, virtualmente foi reduzido ao tamanho que cabe na imagem, numa tela. As coisas se tornaram planas, próximas e longe, no mesmo plano, sem curvas ou profundidades. A realidade se tornou uma sequência de imagens. O relevo virou uma espécie de alma da pintura, que não dá para tocá-la, ir até ele fisicamente, mas está lá, permite ser imaginado, visto em uma dimensão 3D e até bem observado com esforço mental.

Como captar a informação necessária para o marketing nessa perspectiva? Não dá para pegá-la mesmo ela estando ali. Ela pode ser imaginada e até bem observada num esforço da mente, mas não tem curvas nem profundidade. E mais, se a informação for real, talvez não seja mais um parâmetro da realidade, apenas uma aparência, uma imagem. Não é uma tarefa fácil. A clássica forma de captação e mensuração quantitativa fica cada vez mais irreal considerando-se esses novos atributos. Mas seguir os rastros e suspeitas, também é difícil. Afinal, o que seguiríamos? O real ou o virtual? $\mathrm{O}$ próximo ou o distante? A que espaço teríamos que nos ater: ao espaço geográfico ou ao ciberespaço? Tudo ao mesmo tempo, responderiam os autores pós-modernos. Tarefa árdua e espinhosa.

É a complexidade complicando a tarefa do planejador e do pesquisador. Avançam sobremaneira as entidades híbridas. São situações em que o real e o não real parecem ser a mesma coisa. Novos habitantes fazem parte do nosso espaço: ícones, mouses, roteadores levam à emergência de realidades artificiais como forma de apresentar um novo ambiente. A hipertrofia da imagem com comandos informatizados e modelos matemáticos "faz a imagem fazer" coisas que, no real, não faria, faz com que ela não seja mais só representação, mas apresentação com vida própria e tende a não parar nunca mais 
de avançar. A representação está assumindo o lugar do objeto representado, numa forma mais ideal que o próprio "objeto" ou "ator". O virtual como uma nova dimensão do real, e não, seu substituto (Weissberg, 1993). Como já dito, estamos na era do fazer, nesse caso, fazer-parecer com o real, ou fazer-ser melhor que o real.

Imagens infográficas imitam a natureza, traduzem teorias de forma sensível ou nos desconcertam com imagens fragmentadas e, aparentemente, sem sentido. Linguagens simbólicas permitem essas imagens sínteses, essencialmente abstratas, uma aliança entre a forma e o sensível. A numeralização e a virtualização da informação fizeram crescer o papel da tecnologia de representação na sociedade. A imagem deixa de ser metáfora para ser modelo de um caráter mais concreto e experimental à teoria. $\mathrm{O}$ modelo pode ser experimentado, testado, confrontado com o real. A imagem síntese é uma versão equivalente ao modelo. A infografia, com sua capacidade de interagir com o espectador, é a grande revolução, que significa imersão interativa. Exemplo: simuladores de voo. A imagem síntese acrescenta uma impressão física forte, envolvente, muito próximo do real, parecendo ser "mais real que o real" (Quéau, 1993).

O marketing, como teoria e ferramental de atuação, precisa considerar todas essas novas perspectivas. É necessário que o marketing desmonte e remonte seu ferramental e suas formas de aplicações, incluindo essa nova perspectiva.

Um desmontar, e, posteriormente, um remontar do marketing levando em conta que na pós-modernidade, não se vive mais um ambiente de tempo e de espaço harmônico. Vive-se uma nova sensação de irrealidade, com vazio e confusão, onde se cultua o "des" predomin (Santos, 1988): desencanto; desordem; descrença; deserto; desreferencialização do real; desregulamentação da economia; desestelização da arte; desconstrução da filosofia; despolitização da sociedade; dessubstancialização do sujeito; descompromisso; desmantelamento; desregramento e muitos outros “des". Nesse ambiente, onde o "des" é regra, resulta um ambiente onde a "in" faz parte do dia a dia: a incerteza (Santos, 1988).

Numa perspectiva do marketing e da informação, poderíamos dizer que o primeiro terá de perceber que o que aparentemente é informação pode ser desinformação ou apenas informação despolitizada, desordenada, descompromissada, desreferenciada, ou outro 'des' qualquer. Isso torna a informação imperfeita e assimétrica por ficar ‘in’: incompleta, incerta e insegura.

Essa obscuridade, ou incerteza, aparenta ser contraditória, se considerarmos Baudrillard (1992), que diz que, na pós-modernidade, estamos transparentes, iluminados por todos os lados a ponto de perder nossa sombra. Estamos superexpostos pelas técnicas, pelas imagens e pelas informações. Como 
não temos refratários, absorvemos tudo, branqueando corpos, mentes e memórias. Aparentemente, seria mais fácil ver a "verdadeira informação" mediante tanta "iluminação e transparência". Mas não é bem assim. Por que isso nos nos leva a fazermos apenas atividades brancas, sociabilidade branca, vivendo numa assepsia total. "Cirurgia estética" (aparência), "branqueamento" (superficialidade), incerteza radical, simulação indefinida e proibição da negatividade são os caminhos disponíveis. Para isso, "cirurgias amputam" traços negativos do corpo e da mente. Somos remoldados por operação de síntese para ficar mais no estilo ideal, aparentemente mais agradáveis aos olhos e aos ouvidos. Praticamente mata-se o ser humano, e ele se transforma uma redenção geral de signos, aparência, conveniência, estética e imagem. Quase nada sobra do humano anterior que foi sacrificado em nome da geração operacional, das coisas, pela causa, pela meta, pelo objetivo (Baudrillard, 1992).

Nesse caso, a perspectiva do marketing e da informação terá que analisar com quem está se relacionando, para quem está planejando e agindo. Também de quem vem, ou para quem vai, a informação. Estará se direcionando ao ser humano ou a esse outro ser "híbrido remodelado", redimensionado? Cabe ao marketing reatualizar seu conhecimento, saber, teoria e forma de observar a informação nesse novo contexto de mais aparência e menos essência.

Esse novo ser hibrido faz parte da chamada sociedade da informação, onde surgem os "novos homens do saber" e os "novos saberes" baseados na informação. A função $\mathrm{Y}=\mathrm{f}(\mathrm{K}, \mathrm{L})$ dá lugar a $\mathrm{Y}=\mathrm{f}(\mathrm{S}, \mathrm{I})$, com a riqueza produzida sendo agora função do saber e da informação. Isso deveria permitir uma sociedade que infoinclua, mais livre, igual e fraterna. Resgataria a ideia original do ciberespaço, em que 'cyber' vem do homem do leme. Esse homem do leme daria seu rumo num espaço de novas fronteiras. Todavia, essas promessas utópicas não passaram de sonho. O ciberespaço virou poluição da velocidade, reduziu o mundo a um universo virtual paralelo, criado e sustentado por computadores interligados em redes, num espaço controlável e manipulável. A pergunta que surge é: controlável por quem, de quê, por quê e para quê? Houve evolução tecnológica, mas exercício de poder não mudou. Continua o controle, desigual e excludente (Serra, 1998).

Existe um grande hiato entre o superdesenvolvimento das tecnologias e o desenvolvimento institucional e social. As instituições ainda são modernas, duras, rígidas e, nem sempre, dão conta dessa nova realidade. Muitas teorias também. Quanto ao social, é importante destacar a presença ainda muito forte da exclusão do acesso das mais diversas formas e as várias coisas, inclusive as tais novas tecnologias. O pós-moderno não é ainda o sonhado plenamente includente (Pinho Neto, 2008). 
Com essa preocupação, também precisam ser contextualizados "o novo marketing" e a "nova informação". É preciso sempre se perguntar se o que surge de novo é autêntico e espontâneo ou está à serviço do controle, da manipulação e do poder? Se surgiu para incluir ou excluir? Inclusive, a informação captada pode ser pretensamente produzida daquele modo porque interessa ao controlador, ao manipulador e ao poder. Nesse caso, seria algo bem "real" (o poder controlador) controlando um ambiente virtual. Pode-se então dizer que toda riqueza produzida agora predominantemente pelo saber e pela informação é produzida a serviço de interesses, digamos escusos. A exclusão tecnológica também teria este viés. Nesse contexto, surge outra pergunta: é possível acreditar na informação que é gerada? Ela continuaria tendo "somente os velhos defeitos" (incompleta, assimétrica, imperfeita, imprecisa) ou também teria "novos/velhos defeitos" como intencional, branqueada, manipulada, ficcional, superficial, irreal, incerta, incorreta, dúbia e falsa?

Toda essa complexidade não deve levar ao desespero nem a desistência. Esses dois "des" não servem na atuação pós-moderna. Agora um "des" propositivo é recomendável: o despertar. Despertar a atenção e o cuidado com as informações que balizarão a atuação do marketing na pós-modernidade.

As inovações tecnológicas que geram o aqui (espaço) e o agora (tempo) mudaram as relações, formaram uma lógica da aceleração, da velocidade e de novos híbridos. Gerando assim três incidências (com interrogações) contraditórias: as redes (promovem o fim dos vínculos territoriais?); a Internet (desvanece os intermediários do espaço público?) e o regime temporal das tecnologias (acelera e retarda?). Fato é que a telepresença é um paradigma cultural pós-moderno, ligado a desterritorialização (Weissberg, 1993).

Trazendo essa argumentação para o marketing, percebe-se que essas três perguntas são relevantes porque mexem em seu mais tradicional modelo, o seu famoso composto de marketing, ferramental conhecido como os 4Ps do marketing (produto, preço, praça e promoção). Esse modelo surgiu e evoluiu num contexto ainda moderno: anos 50 até meados dos anos 70 . O modelo dos 4Ps, a partir de então, dominou o cenário dos estudos do marketing e permanece atual, embora já não tão unânime como outrora. Contextualizando do referido modelo com as três incidências contraditórias observadas por Weissberg (1993), vê-se que elas impactam em mudanças internas na forma de pensá-lo, especialmente nos itens promoção (comunicação integrada de marketing) e praça (ponto, local, logística, distribuição), sem isentar os outros dois (produto e preço).

Isso porque, num contexto de desterritorialização, de ciberespaço, de internet e de redes virtuais, como se deve pensar praça e promoção? Onde estaria a praça? No ciberespaço? Se for isso, como localizar o ponto ou o local 
de atuação? Na tela do meu computador? E como fazer a logística e a distribuição? Como fica o mercado tradicional? No P de promoção continuaria a comunicação integrada de marketing ou ela passaria a ser desintegrada? Algumas dessas indagações o marketing já respondeu, em outras, inclusive, já se adaptou, mas o processo está distante de ser completo e de se ter certeza de que evoluiu suficientemente. Nada mais pós-moderno do que isso: incompleto e incerto.

\section{Adequando o PLANEJAMENTO DE MARKETING NA PÓs-MODERNIDADE}

Depois de tudo o que foi relatado ainda vale a pena planejar ações de marketing? Evidentemente que essa missão deve continuar, mas agora adequada à nova realidade. Planejar, normalmente, vem antes de agir. Ao menos, era normal até então. Isso porque a nova configuração caótica típica da pós-modernidade, não deixa isso mais tão evidente, sobre o que vem primeiro e depois (ordenação).

Segundo Chesneaux (1989), na pós-modernidade, a partida já é a própria chegada, tudo está presente em toda parte, nada em lugar nenhum, tudo é artificial e virtual. Degradou-se o espaço temporal, aqui, ali, lá, dentro, fora, próximo, distante, antes, agora, depois. Estamos num hiperespaço de acesso direto, instantâneo e generalizado (Chesneaux, 1989).

O planejamento do marketing precisa se adequar a algo que não é simples. Afinal, ver o tempo como o agora quebra um importante pressuposto do planejamento: o ato de pensar no presente sobre o futuro, o pensar para depois agir. E segundo Bourdieu (1997) o pensar, por si só, tem uma pitada de subversivo, desmonta ideias prontas, faz encadeamentos, apela para a razão, para o conteúdo e para as demonstrações. Para isso precisa de tempo, que agora não se tem mais. Ainda assim, segundo Sina (2008: 20) a teoria do marketing tem acompanhado e evoluído o mercado, "sem deixar de considerar seus fundamentos, conceber, planejar e executar ações capazes de expandir [...], criar valor, agregar valor".

Se antes, planejar as estratégias do marketing, executar o plano, obter os resultados da ação e avaliar eram ações linearmente e temporalmente pensando, na atualidade, isso não deve ser feito, necessariamente, numa forma escalonada e linear nem com a mesma rigidez e as "certezas" de outrora. Cada vez mais a terminologia "in" toma corpo especialmente na incerteza, e a terminologia "des" predomina em quase todas as situações. Como o planejamento estratégico de marketing é uma forma de se organizar e pensar no futuro em sintonia com o que se vê no presente e no passado, fica explícito 
que se trata de uma forma de ordem e organização. Todavia, no ambiente pós-moderno prevalece a desordem e a desorganização. Mas também se sabe que toda desordem causa uma nova ordem, ou novas ordens, raramente idênticas às anteriores. Então, depois da ruptura causada pela "desordem", um novo cenário se cria (nova ordem) e é a partir disso que deve se pensar o planejamento. Como? Mudando, inclusive, a forma de planejar. Está em xeque a cronologia do planejar e não o planejar em si.

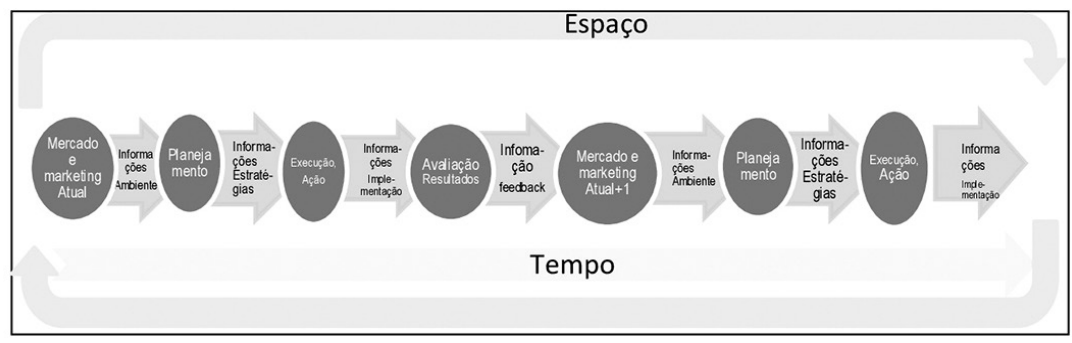

Figura 1. Cronologia Tradicional do Planejamento Estratégico de Marketing Fonte: Elaboração dos autores

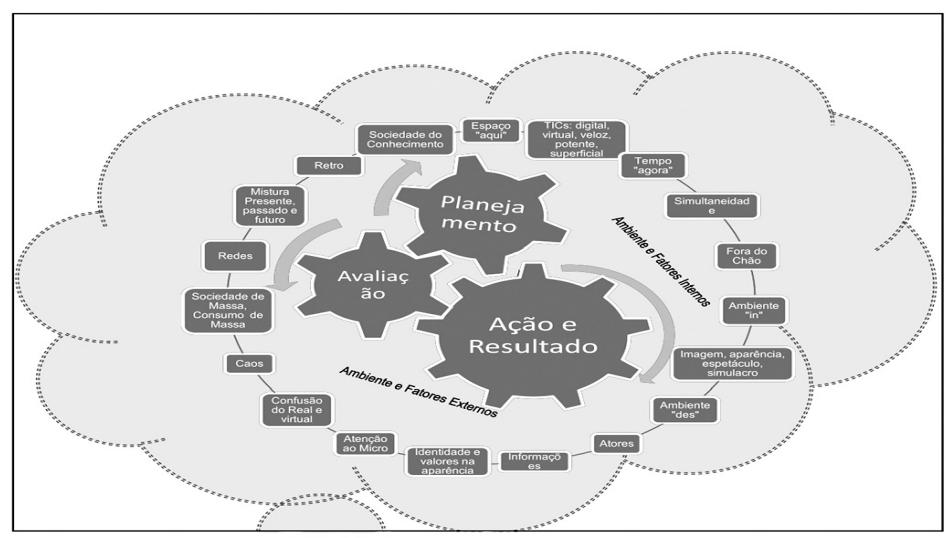

Figura 2. Novos dimensionamentos do planejamento do marketing na pós-modernidade Fonte: Elaboração dos autores

Nesse novo ambiente do marketing, continua sendo importante o planejamento, a execução, o resultado e a avaliação para repensar o planejamento e executá-lo. A diferença é que tudo acontece ao mesmo tempo. É um continuum. Não é um processo encadeado, mas todos se encadeiam ao mesmo tempo, se autoinfluenciam e influenciados tudo em tempo real. O próprio ambiente é instável ao se definir o que é interno ou externo. O formato 
externo em forma de nuvem busca demonstrar que não é nem linear nem circular o processo, mas pode tomar várias formas, assim como as nuvens mudam com os ventos. O fato de a área externa estar cercada por linha pontilhada significa que ela é vulnerável e instável tanto ao que vem de fora como ao que vem de dentro.

Assim cronologia, na pós-modernidade, deixa de ser uma linha contínua para ser um rizoma ou, mínimo, uma linha torta.

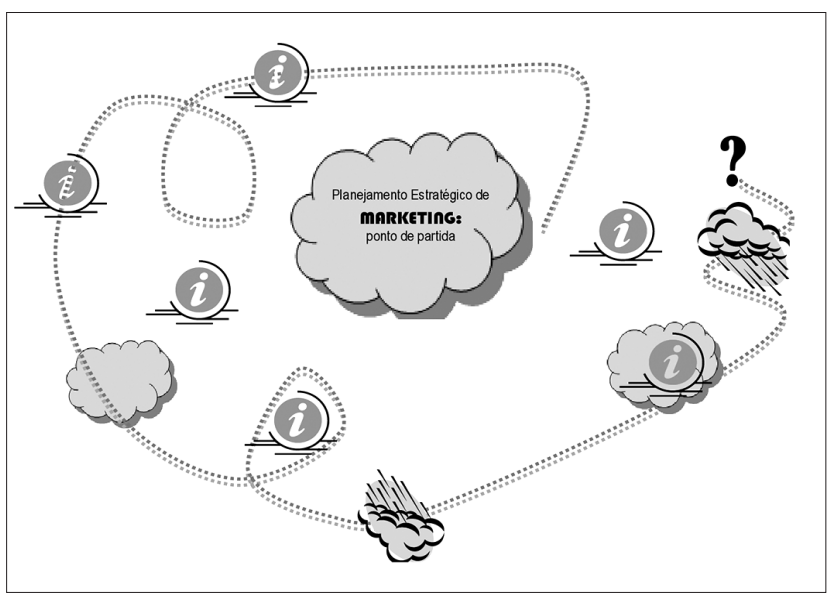

Figura 3. Possível ambiente, caminho e cronologia que encontrará o marketing oa se planejar na Pós-modernidade

Fonte: Elaboração dos autores

Planejar o marketing, nesse novo cenário, exige seguir a direção de onde a informação está e enfrentar diversos cenários. Nem sempre se encontrará a informação necessária, às vezes, se passará ao largo dela, outras vezes, rodeá-la-á, sem conseguir retirar dela o que precisa e, por causa disso, se pagará um preço (situações torrenciais, avessas,...). Ser planejador de marketing, na pós-modernidade, é se adaptar o tempo todo; é seguir o rastro da informação adequada, por mais difícil que seja; é saber que o caminho não é tão bonito como o cenário inicial imaginado (por isso no desenho está pontilhado ou vazado); é admitir que a incerteza faz parte do processo. O importante é nunca parar e ficar o tempo todo, simultaneamente, planejando, agindo, observando resultados, avaliando e retroalimentando. Não existe mais o cidadão que acorda de manhã e diz: "Hoje vou pensar e planejar o futuro", ou o que afirma: "Hoje vou executar um dos itens previstos no planejamento construído no passado". O cidadão já acorda sabedor que terá que fazer todas as atividades permanentemente. 


\section{CONSIDERAÇÕES FINAIS}

Neste artigo, procedeu-se a uma reflexão sobre novos ambientes para se planejar e executar o marketing e os novos pressupostos do uso da informação na pós-modernidade. Se, no passado, fazia-se um planejamento para 10, 15 ou 20, se recentemente se admitia o curto prazo como sendo o tempo de até um ano, médio prazo, de até três anos, e longo prazo, de até cinco anos, com a pós-modernidade, esses prazos não se distinguem mais tão claramente.

Há algumas décadas, as máquinas eram fabricadas para atuarem por até 30 anos. Na atualidade imaginar a vida útil de uma máquina por mais de cinco anos é desnecessário, pois se ela resistir em termos de vida útil, mesmo assim estará obsoleta tecnologicamente. O argumento da qualidade pela resistência e da durabilidade perdeu força para o descartável e o atualizado.

O planejamento estratégico de todas as áreas e do marketing também observam seus prazos se encolhendo. A última trincheira de resistência é essa transição para o aqui e o agora, para o simultâneo. Planejar também é o agora. Acontece, simultaneamente, com executar o plano.

Então, qual o papel da informação nesse planejamento pós-moderno? Continua o mesmo: alimentar o planejamento para ele tenha condições de retratar o que, de fato, precisa ser considerado naquela realidade. A informação continua a principal aliada do planejamento e da execução do marketing, porque dela sempre virão os "rastros" e as "suspeitas" que permitirão importantes antecipações de situações. Mesmo que essa antecipação não seja apenas de dias, horas, minutos ou até milésimos de segundos. Mas já é uma antecipação.

Podemos ter certeza de que tudo funcionará adequadamente como planejado? Não. Na pós-modernidade a única certeza é que teremos incerteza.

\section{REFERENCIAS}

AMA (American Marketing Association). 2018. Definition of Marketing. https://www. ama.org/AboutAMA/Pages/Definition-of-Marketing.aspx

Barreto, A. M. 2005. "Informação e Conhecimento na Era Digital”. Transinformação 17 (2): $111-122$.

Baudrillard, J. 1992. "A brancura operacional”, em A transparência do mal: ensaios sobre os fenômenos extremos, 2. ed., 51-57. São Paulo: Papirus.

Bembem, A. H. C., P. L. V. A. C. Santos e J. A. S. Pinho Neto. 2014. “Tempo do Conhecimento Interativo: Reflexões sobre a Inteligência Coletiva e o Pensamento Complexo”. Em Questão 20 (1): 12-31. 
Bourdieu, P. 1997. "O Estúdio e seus Bastidores", em Sobre a Televisão, 16-54. São Paulo: Editora Zhar.

Chesneaux, J. 1989. “Uma Outra Relação com o Espaço e com o Tempo”, em Modernidade-Mundo, 17-40. Petrópolis: Vozes.

Freitag. B. 1986. Teoria crítica: ontem e hoje. São Paulo: Brasiliense.

Hooley, Graham J., J. A. Saunders e N. F. Piercy. 2001. Estratégia de Marketing e Posicionamento Competitivo, 2. ed. São Paulo: Prentice Hall.

Keegan, W. J. e M. C. Green. 2013. Marketing Global. São Paulo: Saraiva.

Latour, B. 1994. Jamais Fomos Modernos: Ensaio de Antropologia Simétrica. Rio de Janeiro: Editora 34.

Latour, B. 2012. Reagregando o social: uma introdução à Teoria Ator-Rede. Salvador: Edusc.

Lèvy, P. 1999. Cibercultura. São Paulo: Editora 34.

Matos, O. C. F. 1989. Paris 1968: as barricadas do desejo. Tudo é história 9. 3. Ed. São Paulo: Brasiliense.

McKenna, R. 1992. Marketing de relacionamento: estratégias bem sucedidas para a era do cliente. Rio de Janeiro: Campus.

Monteiro, S. D. e J. G. Abreu. 2009. "O Pós-Moderno e a organização do conhecimento no ciberespaço: agenciamentos maquínicos”. DataGramaZero 10 (6) (dez.). Acesso em 05 dec. 2014. http://www.dgz.org.br/dez09/Art_05.htm

Perrotti, E. e I. Pieruccini. 2014. "A mediação cultural como categoria autônoma”. Revista Informação E Informação 19 (2) (maio/ago.): 1-22. Acesso em 02 oct. 2015. http:www.uel.br/revistas/informacao/

Pinho Neto, J. A. S. 2008. "As Novas Tecnologias de Comunicação e Informação da Transversalidade entre Natureza e Cultura”. Revista Culturas Midiáticas 1 (1): 1-11.

Quéau, P. 1993. "O Tempo do Virtual”, em Imagem-Máquina: A era das tecnologias do virtual, A. Parente (org.), 91-99. Rio de Janeiro: Editora 34.

Sabbag, P. Y. 2007. Espirais do conbecimento: ativando individuos, grupos e organizações. São Paulo: Saraiva.

Santos, J. F. 1988. O que é Pós-Moderno, 5. ed. São Paulo: Brasiliense.

Satur, R. V., S. B. Paiva e E. N. Duarte. 2017 "Informação imperfeita e seu impacto nas estratégias empresariais". Brazilian Journal of Information Studies: Research Trends 11 (2): 07-18. Acesso em 01 jun. 2014. http://www2.marilia.unesp.br/revistas/index.php/bjis/article/view/5057

Serra, J. P. 1998. A informação como utopia. Covilhã (PT): Labcom Books.

Sina, A. 2008. Marketing global: soluções estratégicas para o mercado brasileiro. São Paulo: Saraiva.

Sousa, R. P. M., G. A. Dias, B. Oliveira e M. Sousa. 2013. “O exercício da arquitetura da informação na Web: reflexões relativas à Lei dos Direitos Autorais”. Encontros Bibli 18 (36) (jan./abr.): 107-128.

Stewart, T. A. 1998. Capital Intelectual. Rio de Janeiro: Campus.

Trigo, M. R., B. Soares e L. M. Quoniame. 2012 "Inteligência competitiva e inovação estratégica: A IC acompanhando a evolução mundial”, em Gestão da informação, inovação e inteligência competitiva: como transformar a informação em vantagem competitiva nas organizações, C. Starec (org.), 59-78. São Paulo: Saraiva, pp. 59-78.

Vargo, S. L. e R. F. Lusch. 2011. "It's all B2B and Beyond: Towards a Systems Perspective of the Market”. Industrial Marketing Management 40 (2): 181-187. 
Virilio, P. 1993. O espaço crítico e as perspectivas do tempo real. Rio de Janeiro: Editora 34. Weissberg, J. L. 1993. "Real e virtual”, em Imagem-Máquina: a era das tecnologias do virtual, A. Parente (org.), 117-126. Rio de Janeiro: Editora 34.

\section{Para citar este texto:}

Satur, Roberto Vilmar, Júlio Afonso Sá de Pinho Neto y Emeide Nóbrega Duarte. 2018. "Redimensionamento do espaço e do tempo: a incerteza o es desafios da sociedade, da informação e do planejamento do marketing". Investigación Bibliotecológica: archivonomía, bibliotecología e información 32 (77): 151-173.

http://dx.doi.org/10.22201/iibi.24488321xe.2018.77.57942 